\title{
VINYON "N" AS DURAL SUBSTITUTE AND ITS USE IN OTHER NEUROSURGICAL CONDITIONS
}

\author{
BY \\ PAUL TENG \\ From the Neurosurgical Service, Kaiser Foundation Hospital, Los Angeles, California
}

The search for a material to be utilized as dural substitute has been a continuous one for the last six decades. Many materials have been tried, including the different metals, various biological tissues, and plant derivatives. Recently, synthetic products have been utilized as dural substitute. Among these, Vinyon "N" (Teng and Feigin, 1955), Teflon (Teng, unpublished data), and Orlon* (Huertas, 1955) have shown the most promising results, producing only minimal tissue reaction when buried intracranially in experimental animals.

Since publication of the results obtained in experimental monkeys, Vinyon " $N$ " has been used in 40 clinical cases with various neurosurgical conditions, which included its use as (1) dural substitute in repairs of dural defects produced by surgery, trauma, or tumour; (2) bone lining, in the prevention of bone reunion in craniostenosis; and (3) nerve wrap after neurolysis in cicatrization (Table I).

TABLE I

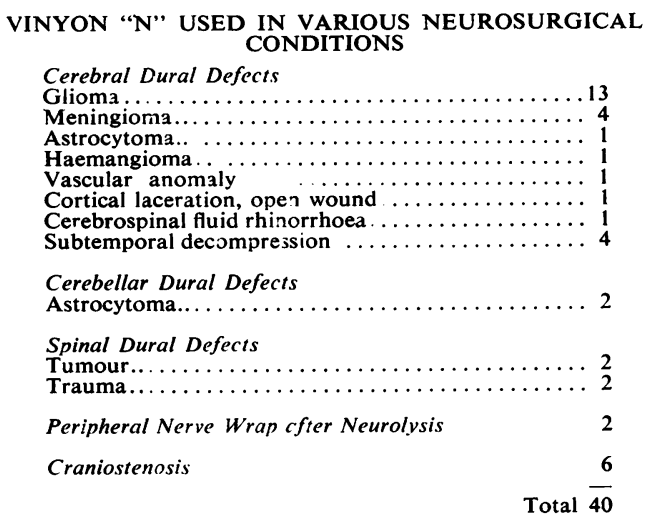

Vinyon "N" Cloth

The Vinyon " $N$ " used in these experiments, is a synthetic fabric woven into cloth, constructed of

*The Vinyon " $N$ " cloth used in this study was supplied by the Carbido and Carbon Chemical Company, New York.
144 wrap threads and 90 filling yarns per squar $\$$ inch. The pattern weave, consistency, and coloug are those of China silk. It can readily and repeatedly be sterilized in boiling water without any appreciable damage. Autoclaving stiffens it.

\section{Clinical Observations}

From February, 1956, to July, 1960, Vinyon "Ni cloth has been used in 40 neurosurgical cases. I I 32 instances it was used as dural substitute. These included 26 cerebral dural defects, two cerebellario dural defects, and four spinal dural defects. In sif infants it has been utilized as bone lining aftep a "grooving" craniectomy for craniostenosis. It has also been used in two patients as nerve wrap, io sciatic trunk and a radial nerve, after neurolo sis in severe cicatrization. The duration of observatiof in these 40 cases varied from four to $52 \frac{1}{2}$ months (Table II).

As Cerebral Dura Substitute.-Vinyon "N" clot has been used to cover cerebral dural defects in $26^{\circ}$ clinical cases, which included 13 malignant gliomas four meningiomas, four subtemporal decomprest sions, and one case each of astrocytoma, cerebro5 spinal fluid rhinorrhoea, cortical laceration, vasculap anomaly, and haemangioma (Table I). In each instance, the Vinyon " $N$ " cloth was tucked under the edge of the dura (Fig. 1B). The technique use in applying Vinyon "N" cloth as a dural substitute has been described in detail in a previous paper o animal experiments (Teng and Feigin, 1955 Meningocerebral adhesions frequently developed along the suture line in edge-to-edge anastomosis (dura to Vinyon "N"), but no such adhesions occurred in eversion suturing or when tucking the edge of dural substitute under the edge of dura mater. This technique has been followed in all cases of this series.

In 15 cases, it was possible to recover the Vinyou "N" cloth from the site of surgery. These includeg 13 cases of malignant glioma at necropsy, and 182 
TABLE II

VINYON "N" CLOTH RESIDENT IN TISSUE

\begin{tabular}{|c|c|c|c|c|c|c|c|c|}
\hline Case No. & \multicolumn{3}{|c|}{ Manner of Utilization } & \multicolumn{3}{|c|}{ Diagnosis and Site of Vinyon "N" Used } & $\begin{array}{c}\text { Date of } \\
\text { Operation }\end{array}$ & $\begin{array}{c}\text { Approximate } \\
\text { Duration to } \\
\text { July 1, } 1960 \\
\text { (mth.) }\end{array}$ \\
\hline $\begin{array}{l}1 \\
2 \\
3 \\
4 \\
5 \\
6 \\
7 \\
8 \\
9 \\
10 \\
11 \\
12 \\
13 \\
14 \\
15 \\
16 \\
17 \\
18 \\
19 \\
20 \\
21 \\
22 \\
23 \\
24 \\
25 \\
26 \\
27\end{array}$ & 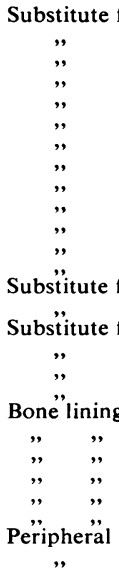 & 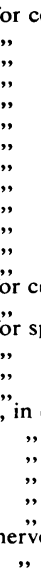 & $\begin{array}{l}\text { bral dura } \\
",\end{array}$ & \multicolumn{3}{|c|}{$\begin{array}{l}\text { Left parieto-occipital astrocytoma } \\
\text { Left temporal lobe haemangioma } \\
\text { Left frontal meningioma } \\
\text { Left frontal parasagittal meningioma } \\
\text { R̈ight frontal parasagittal meningioma } \\
\text { Left parietal vascular anomaly } \\
\text { Right temporoparietal laceration } \\
\text { Right subtemporal decompression } \\
\text { Left subtemporal decompression } \\
\text { Fe ,ontal base, cerebrospinal fluid rhinorrhoea } \\
\text { Right cerebellar astrocytoma }\end{array}$} & $\begin{array}{r}6 / 3 / 58 \\
1 / 23 / 57 \\
8 / 6 / 56 \\
5 / 26 / 56 \\
11 / 14 / 57 \\
8 / 14 / 57 \\
5 / 14 / 16 \\
10 / 5 / 56 \\
8 / 15 / 56 \\
8 / 21 / 56 \\
11 / 17 / 56 \\
12 / 29 / 57 \\
5 / 3 / 57 \\
2 / 29 / 56 \\
6 / 5 / 59 \\
11 / 19 / 58 \\
4 / 19 / 57 \\
11 / 20 / 57 \\
6 / 10 / 57 \\
2 / 15 / 56 \\
3 / 4 / 56 \\
5 / 6 / 57 \\
9 / 1 / 59 \\
9 / 12 / 59 \\
9 / 17 / 59 \\
4 / 9 / 57 \\
4 / 29 / 59\end{array}$ & $\begin{array}{l}25 \\
41 \\
47 \\
49 \\
31 \frac{1}{2} \\
34 \frac{1}{2} \\
49 \frac{1}{2} \\
45 \\
46 \frac{1}{2} \\
46 \frac{1}{4} \\
43 \frac{1}{2} \\
30 \\
38 \\
52 \\
13 \\
19 \frac{1}{3} \\
38 \frac{1}{3} \\
31 \frac{1}{3} \\
36 \frac{3}{3} \\
52 \frac{1}{2} \\
52 \\
38 \\
10 \\
9 \frac{1}{2} \\
9 \frac{1}{2} \\
38 \frac{2}{3} \\
14\end{array}$ \\
\hline
\end{tabular}

two instances it was recovered from patients undergoing subsequent surgery. In the 13 necropsied cases, the length of time that the Vinyon " $N$ " cloth had been buried in tissue ranged from four to 22 months. In the others, one a case of frontal meningioma and the other a subtemporal decompression, the cloth was removed, in part, for microscopic examination, after being examined in situ. In these two, the dural substitute had been used to cover the dural defect for periods of 34 and 30 months, respectively. None of the 27 patients currently alive reveal any clinical evidence of irritative effect from the synthetic fabric up to the time of writing.

In all of the 15 cases mentioned above, the dural substitute was easily reflected or removed, with or without gentle blunt dissection, as necessary, there being no adhesions at the site of the cerebral wound. Here and there were scattered fine strands of fibrous tissue adherent to cortical vessels, where dissection was needed to lift the dural substitute from the cortex without tearing the pia mater. As a rule, dense scar tissue was found on the outer surface of the dural substitute, but on its under surface there was a thin layer of transparent, glistening membrane, the thickness of an opaque arachnoidea. No connective tissue capsule was found to enclose the dural substitute in any of the 15 cases. Microscopic examination showed the dural substitute to be infiltrated by a few lymphocytes and foreign body giant cells. Minimal proliferation of the arachnoid cells was noted. The underlying cortex appeared normal. There was no adhesion between the dural substitute and the surgical wound in the cerebrum.

The following case is illustrative:-

This 30-year-old man was operated on on August 6, 1956 (Table II, Case 3). A large meningioma, en plaque, was removed through a left frontal craniotomy. Both the bone flap and the dura were discarded because of tumour infiltration. The frontal bone measured 1.5 in. in thickness. Hyperosteosis extended to the left supraorbital plate and the ocular globe was displaced downward. A piece of Vinyon " $N$ " cloth, $3 \times 3$ in. in diameter, was used to cover the dural defect.

Two years and 10 months later he was again operated upon for removal of the remaining portion of left frontal bone, supra-orbital rim and plate, and the nasal bone. The frontal wall of the cranium and the orbital rim were reconstructed with grafted ilium. At surgery, the Vinyon "N" cloth was examined. Dense fibrous tissue was found on the outer surface of the dural substitute, but its under surface was covered only by a thin layer of fibrous strands which were not adherent to the underlying cortex. In places, the dural substitute was loosely anchored to the cortical vessels by thin strands of connective tissue which were easily separated by dissection, without tearing the pia membrane and cortex. In one small area, where the cortex was not covered with dural substitute, dense scar tissue was found, extending from the epidural region to the cerebral cortex, with abundant traversing vessels.

A small piece of Vinyon "N" cloth, excised for microscopic examination, showed scattered lymphocytes and foreign body giant cells lodged among the meshes of the 


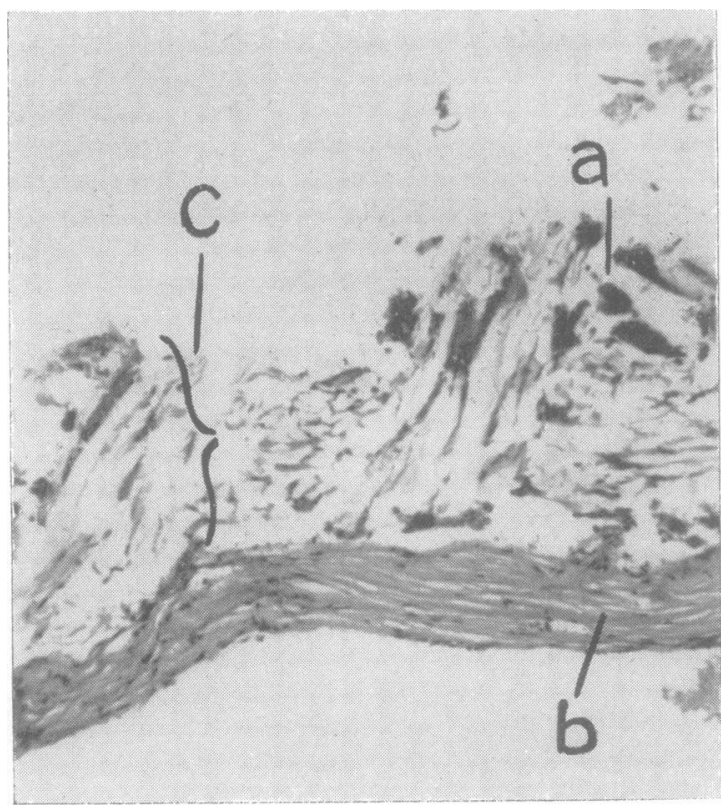

FIG. 2.-Section of dural substitute, Vinyon "N", removed 34 months later. $\times 80$. (a) large foreign body giant cells; (b) thin layer of fibrous tissue lining under surface; (c) total thickness of silk-like Vinyon "N" cloth.

dural substitute, and a thin layer of connective tissue on its under surface (Fig. 2).

Despite the fine pores of the Vinyon " $N$ " cloth, it has been used to repair rhinorrhoea of the cerebrospinal fluid. The following is an illustration of an extreme case of cranionasal fistula.

A 27-year-old man (Table II, Case 13) was admitted to the hospital on May 1, 1957, because of cerebrospinal fluid leaking through the nose for two years, after a motorcycle accident. He had survived five episodes of septic meningitis in the past two years. Surgical repair of the fistula had been recommended at another hospital, but this was refused. On May 3, 1957, a right frontal craniotomy was performed, and a large bone and dural defect, $1.5 \mathrm{~cm}$. in diameter, was found in the cribriform plate. Granulations in the fistula were curetted, then packed with gelfoam soaked with bacitracin and polymyxin solution. A small piece of Vinyon "N" cloth was laid on the inner surface of the dural defect. The postoperative course was uneventful, and no cerebrospinal fluid has leaked since surgery.

As Cerebellar Dural Substitute.-In two cases of cerebellar astrocytoma, after removal of the tumour, the dura was not resutured but the cerebellum was covered with a piece of Vinyon " $N$ " cloth, placed in a position similar to that used to cover the cerebrum. Neither of the patients, after 13 and 52 months respectively, show any ill effects since its placemento in the posterior fossa.

As Spinal Dural Substitute.-Vinyon "N" hasō. been used to cover spinal dural defects in four cases In three instances it was placed after decompression of the spinal cord or cauda equina. Compression? was caused by trauma in two of the cases, and tumour in the other. In the two patients with compression of: the cauda equina caused by a compression fractures of the upper lumbar spine, the roots of the caudas. equina were markedly congested and swollen. The dura was left open for the purpose of decompression $\overline{\bar{p}}$. and a strip of Vinyon " $N$ " cloth was placed to covero the dural defect. The dural defect in the third patien was produced by excision of a meningioma. In alP three cases the dural substitute has been in place fop periods ranging from $19 \frac{1}{3}$ to $36 \frac{1}{3}$ months, and none have demonstrated any irritative effect.

One case of spinal dural substitute is illustrate below:

This 36-year-old male school taacher (Table II, Case 17. went to surgery on April 19, 1957, where a $C_{2}$ to $C_{6}^{-}$ laminectomy was pərformed, and a large intramedullarfo haemangioma was found. Excision of the tumour was deemed infeasible. The cervical cord was hugely distended by tumour, its width measuring approximately $1.54 n_{\text {. }}$ The tumour extended from $C_{2}$ to $C_{5}$. Multiple postefo incisions were made in the distended cord, and the dura left open for the purpose of decompression. A piece्coto dural substitute, $1 \times 4$ in., was sutured to the durast cover the exposed section.

Before exploration, the patient was quadriplegios After surgery, he regained the limited use of both uppes limbs. Up to the time of writing, he is able to feed himo self and can roll his own wheelchair. The Vinyon " $\mathrm{N}_{2}$ material, buried in the spinal canal for $38 \frac{1}{3}$ months, ha\& not produced any untoward effect.

As Nerve Wrap in Cicatrization.-One of the aims of neurolysis is to prevent recurrence of compressiog by regrowth of scar tissue along the course of the dissected nerve. It has often been a problem t $\overline{\mathrm{Q}}$ find a healthy soft tissue bed for transplantation of the nerve after neurolysis, in cases of severe an\& extensive cicatrization. In this series, two cases of cicatrization of a major nerve trunk, one a sciatie nerve and the other a radial nerve, were treated with neurolysis and wrapping with Vinyon "NS cloth. The purpose of using a nerve wrap in thes cases was to prevent scar tissue infiltration of the. nerve.

The case of cicatrization of the sciatic nerve illustrated in the following:

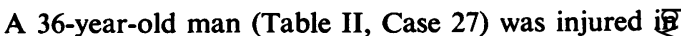
World War II (1944) by a shell wound in the right posterian 

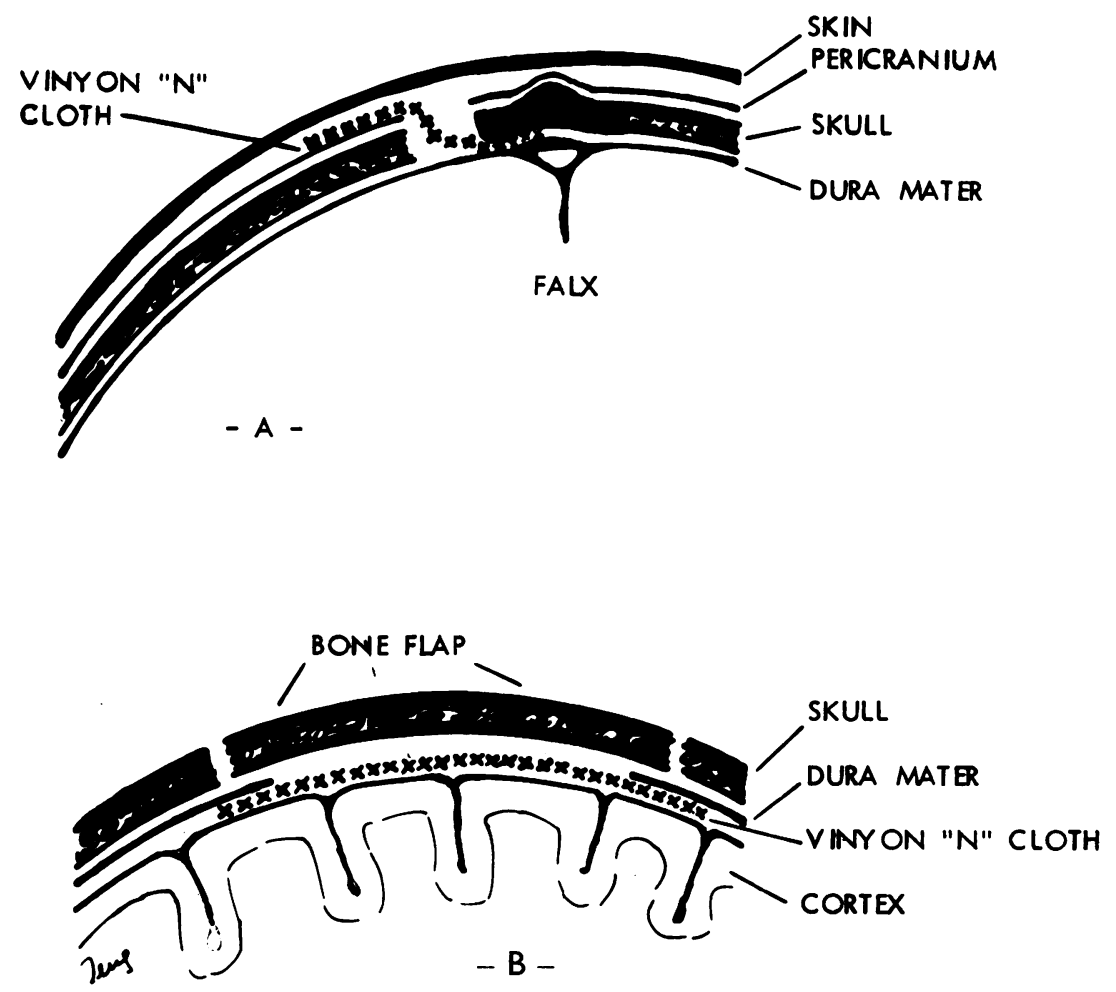

FIG. 1.-Diagram of intracranical use of Vinyon " $N$ " cloth. (A) As bone lining in craniostenosis. Line of cross indicates position of Vinyon "N" cloth lining bone incision. (B) As dural substitute. Note dural cloth tucked under edges of dural defect.

thigh, with subsequent prolonged infection. The right sciatic nerve was partially injured, and pain developed in the right lower leg and foot from this injury. He was operated upon three times at other hospitals, both in the United States and Europe, in an attempt to relieve the pain. After each operation, the pain was partially relieved for a few weeks up to two months, then recurred with increasing severity. For the past one and a half years he has been disabled because of the pain.

On April 29, 1959, the right sciatic nerve in the upper and middle thirds of the thigh was delivered by sharp dissection from an area of extensive cicatrization, which extended through almost the whole thickness of the posterior compartment of the upper thigh, and measured $8 \times 4$ in. in size. The sciatic nerve was wrapped in a tube made of Vinyon " $N$ " cloth, with the upper and lower ends of the tube placed above and below the field of cicatrization.

Since his last operation 14 months ago, the patient has been free of pain, and there is no evidence of irritation to the sciatic nerve caused by the synthetic cloth.

As Bone Lining in Craniostenosis after Craniectomy.-In six infants with craniostenosis, ranging in age from 1 to 7 months, Vinyon " $N$ " cloth was used as bone lining after craniectomy, to prevent reunion of the bone edges. In all six cases only the sagittal suture was prematurely closed. The surgical treatment consisted of a simple unilateral parasagittal bone incision made $1.5 \mathrm{~cm}$. lateral to the midline. The anterior end of the bone incision (or the artifical groove) extended $1.0 \mathrm{~cm}$. beyond the coronal suture, and its posterior end extended $1.0 \mathrm{~cm}$. beyond the lambdoid suture. A thin strip of Vinyon " $N$ " cloth was used to line the bone edges of the craniectomy. The outer half of the Vinyon " $N$ " cloth was tucked under the outer bone edge between the bone and the periosteum-dura, and the inner half of the cloth was buried under the skin medial to the incision between the galea aponeurotica and the pericranium (Fig. 1A). This procedure is simple, and less traumatic than the multiple bone incisions usual in craniostenosis. The shape and contour of the skull appeared normal one to three months after surgery. The cases were followed for a period of nine and a half, nine and a half, $10,38,52$, and $52 \frac{1}{2}$ months respectively. Radiological study showed no evidence of bone union or bony bridges across the incision. Repeated 
clinical examinations revealed no indication of untoward reaction in any of the six cases. Furthermore, Vinyon " $N$ " cloth is soft, silk-like, and it is easy to use in lining the bone edges.

\section{Discussion}

The purpose in using a dural substitute is not specifically for the covering of a dural defect but rather for (1) prevention of meningocerebral cicatrization in cerebral lesions caused by either injury or surgery, (2) repair of cerebrospinal fluid fistulas, and (3) preventing adhesions to the spinal cord or cauda equina in instances where the dura cannot be approximated without tension.

The normal dura has no cellular lining, but a fibrous wall with naked fibroblasts. It is analogous to any connective tissue structures when exposed or damaged, being capable of proliferation or regeneration (Leary and Edwards, 1933). Through this so-called ability of regeneration, the dura can bridge over a wide defect. The regenerated dura is formed mainly by the proliferation of fibroblastic cells in the adjacent soft tissues rather than from the edges of the dural defect. Keener (1959) demonstrated that dural regeneration adjacent to bone, i.e., in the upper calvarium, is inadequate, whereas regeneration is adequate when the dural wound is adjacent to soft tissues such as the temporal or suboccipital muscles. The same cells that can repair a dural defect are also capable of forming scar tissue. The use of a dural substitute, therefore, is not meant to replace normal dura but to prevent extension of scars onto cerebral tissue. Vinyon " $N$ " cloth as a dural substitute satisfactorily serves this purpose. It prevents the formation of meningocerebral adhesions and cross-circulations. Its irritative effect is minimal. This has been adequately demonstrated, both in animal experimental studies and in the clinical applications as described above. The amount of the connective tissue formed between the Vinyon " $N$ " cloth and cerebral cortex, after being buried intracranially three to four years, was minimal. In none of the patients treated in this series has any untoward effect been noted in repeated clinical examinations.

Several authors have stated that one of the qualities of Vinyon "N" cloth which makes it un- suitable as dural substitute, is in its fine pores which $\mathbb{D}$ render it permeable. However, we have found the opposite to be true. In 1953, in animal experiments? with Vinyon " $N$ " cloth, it was originally used as ano. aortic graft, the material being crudely sutured in tube form and anastomosed to the aorta of dogs. For a few minutes, perspiratory drops of blood were seen to penetrate its pores, but shortly afterwards they stopped completely, the pores having been sealed: by blood protein. In like manner, when it is used ass? dural substitute, the exudate of the wound renderso. the Vinyon "N" material waterproof. Furthermore, the dural substitute does not necessarily have to bess waterproof, except when it is used to cover $\mathrm{a} D$ cerebrospinal fluid fistula in rhinorrhoea, and in the latter condition, Vinyon "N" cloth can be used" successfully to seal the fistula.

Its use in craniostenosis, for the prevention of bone reunion after craniectomy, has also shown gratifying results in this series. It is easy to use fo lining the bone incision. For as long as $52 \frac{1}{2}$ months there has been no indication of bone reunion of bridge formation across the bone incision.

In severe cicatrization of peripheral nerves $\overrightarrow{00}$ Vinyon "N" cloth has been used satisfactorily as nerve wrap after neurolysis.

\section{Summary}

Vinyon "N" cloth, a synthetic fabric, has saifs factorily been used as a dural substitute, peripheraf nerve wrap in cicatrization, and bone lining craniostenosis after craniectomy in $\mathbf{4 0}$ clinical casesp The period of observation ranged from four to 52 委 months.

The material is relatively inert and not toxic. is not absorbed, and has a tensile strength like tha of China silk. It can be sterilized by boiling in wate The fine pores in the cloth do not hinder its use if repairing cerebrospinal fluid fistulae, for the serum protein in the wound itself rapidly seals the pore thus rendering it waterproof.

\section{REFERENCES}

Huertas, J. (1955). J. Neurosurg., 12, 550.

Keener, E. B. (1959). Ibid, 16, 424. Leary, (Chicago), 29, 691.

Teng, P. and Feigin, I. (1955). J. Neurosurg., 12, 591. 